\title{
Am I in the right place? : Academic engagement and study success during the first years at university
}

Ketonen, Elina E.

2016-10

Ketonen , E E , Haarala-Muhonen , A , Hirsto , L , Hänninen , J J , Wähälä , K \& Lonka , K 2016 , ' Am I in the right place? Academic engagement and study success during the first years at university ' , Learning and Individual Differences, vol. 51 , pp. 141-148 . https://doi.org/10.1016/j.lindif.2016

http://hdl.handle.net/10138/297756

https://doi.org/10.1016/j.lindif.2016.08.017

cc_by_nc_nd

acceptedVersion

Downloaded from Helda, University of Helsinki institutional repository.

This is an electronic reprint of the original article.

This reprint may differ from the original in pagination and typographic detail.

Please cite the original version. 


\title{
Am I in the right place?
}

\section{Academic engagement and study success during the first years at university}

Elina E. Ketonen ${ }^{a,}{ }^{,}$, Anne Haarala-M uhonen ${ }^{b}$, Laura Hirstoc ${ }^{c}$ J Jari J. Hänninen ${ }^{d}$, Kristiina Wähäläe, \& Kirsti Lonka, ${ }^{a}$

\author{
aDepartment of Teacher Education, University of Helsinki, Finland \\ ${ }^{b}$ Faculty of Law, University of Helsinki, Finland \\ FFaculty of Theology, University of Helsinki, Finland \\ dDepartment of Radio Science and Engineering, Aalto University, Finland \\ eDepartment of Chemistry, University of Helsinki, Finland \\ fOptentia Research Focus Area, North-West University, South Africa
}

* Corresponding author. E-mail address: elina.e.ketonen@ helsinki.fi (E.E. Ketonen).

This is an Author's Accepted M anuscript (AAM) of an article published in Learning and Individual Differences. The final authenticated version is available online at:

http://dx.doi.org/10.1016/j.lindif.2016.08.017

When citing, please refer to the published version:

Ketonen, E. E., Haarala-M uhonen, A., Hirsto, L., Hänninen, J., Wähälä, K., \& Lonka, K. (2016). Am I in the right place? Academic engagement and study success during the first years at university. Learning and Individual Differences, 51, 141-148. 
Abstract

Entrance to university does not automatically lead to high academic engagement and success, and there may be individual differences in student engagement. In the present study, university students' ( $\mathrm{N}=668$ ) academic engagement and disengagement profiles, and the differences between them in terms of academic achievement, were investigated. Students from introductory courses were classified by Latent Profile Analysis (LPA) into homogenous groups having similar patterns according to the following variables: study engagement, study-related exhaustion, lack of interest, lack of self-regulation, and uncertainty of one's career choice. Four groups of students were identified: engaged, disengaged, undecided, and alienated. Engaged students received the highest grades, with disengaged and undecided students performing most poorly. In addition, the profiles were related to the behavioral indicators of engagement (i.e., ECTS credits). Even after two years of studying, engaged students were performing better than disengaged students. The study's implications for both research and practice are discussed.

Keywords: Academic engagement, Self-regulated learning, Academic achievement, University students, Latent profile analysis 


\section{Am I in the right place?}

\section{Academic engagement and study success during the first years at university}

\section{Introduction}

Entering university is a big step for students. A wide variety of dispositions, conceptions, motivational tendencies, and prior knowledge color the way individual students see their new learning environment. The academic environment, in turn, play an important role in how university students experience their studying, and in how they develop intellectually (e.g., Entwistle \& Peterson, 2004; Lonka \& Lindblom-Ylänne, 1996; Trigwell \& Prosser, 1991; Vanderstoep, Pintrich, \& Fagerlin, 1996; Vermetten, Vermunt, \& Lodewijks, 1999; Vermunt, Richardson, Donche, \& Gijbels, 2013). The literature has consistently shown that the first years are the most critical in shaping persistence decisions and in influencing student attitudes (e.g., Astin, 1993; Blythman \& Orr, 2003; Johnson, 1994; M clnnis, James, \& M cNaught, 1995; Pascarella \& Terenzini, 1991; Tinto, 1996).

When the academic context has a good fit with students' interests, expectations, and study practices, the end result should be high engagement, adaptive motivation, and greater wellbeing (Gilbreath, Kim, \& Nichols, 2011; Schmitt, Oswald, Friede, Imus, \& M erritt, 2008; Upadyaya \& Salmela-Aro, 2013). Students whose majors are congruent with their skills and interests are the most likely to persist and succeed (Allen \& Robbins, 2008; Porter \& Umbach, 2006; Tracey \& Robbins, 2006). However, even well-motivated and highly selected students may face problems in regulating their learning (Donche, Coertjens, \& van Petegem, 2010; Donche \& van Petegem, 2009; Heikkilä, Lonka, Nieminen, \& Niemivirta, 2012; Heikkilä, Niemivirta, Nieminen, \& Lonka, 2011; Nieminen, Lindblom-Ylänne, \& Lonka, 2004). Problems in self-regulation may further increase the risk of exhaustion (Litmanen, Loyens, Sjöblom, \& Lonka, 2014; M isra, M cKean, West, \& Russo, 2000).

The aim of the present study was to look at academic engagement and the problems students may face during the decisive first years at university. M ore specifically, we wanted to 
combine the various dimensions of academic engagement and investigate their simultaneous effect on academic achievement. Studies adopting variable-centered approach have indicated how various distinct aspects of student learning are related to educational outcomes (for a review see Richardson, Abraham, \& Bond, 2012). However, such variable-oriented approach describes overall tendencies, behind which differently functioning subgroups of individuals and the complex relations between variables may be concealed (Bergman \& M agnusson, 1997; Reizle, 2013). Thus, we adopted a person-oriented approach (see Bergman $\&$ Andersson, 2010) in order to investigate the complex associations between various dimensions of academic engagement and their combined effect on academic achievement, and most importantly, to identify distinct subgroups of students.

\subsection{The varying dimensions of academic engagement}

Student engagement has become increasingly relevant due to the growing pressure on students to successfully complete their studies within a specific timeframe. A high level of engagement is an important condition for performance and persistence in educational tasks and institutions (e.g., Fredricks, Blumenfeld, \& Paris, 2004). Overall, academic engagement has been the focus of a substantial amount of research in recent years, and has received much attention in varying educational contexts (e.g., Fredricks et al., 2004; Pekrun \& Linnenbrink-Garcia, 2012; Schaufeli, Martinez, Pinto, Salanova, \& Bakker, 2002).

Academic engagement is typically described as a multidimensional construct, but its definitions vary in the literature. Its emotional, cognitive, and behavioral aspects are the mostresearched (e.g., Appleton, Christenson, \& Furlong, 2008; Appleton, Christenson, Kim, \& Reschly, 2006; Fredricks et al., 2004; Jimerson, Campos, \& Greif, 2003). In the present study, academic engagement is understood to include personal meaning and motivation in studying, willingness and ability to self-regulate according to these aspects, and the emotional experiences (i.e., study engagement and exhaustion) that are involved.

Experiencing meaning in one's work has been shown to be a key component in work engagement (Gonzales-Roma, Schaufeli, Bakker, \& Lloret, 2006; Hakanen, Bakker, \& Schaufeli, 
2006). In an educational context, the more cynical the students were (i.e., doubting the significance of their studies), the less they were engaged (Salmela-Aro, Kiuru, Leskinen, \& Nurmi, 2009; SalmelaAro \& U padyaya, 2012; Schaufeli et al., 2002). A cynical attitude may appear as finding a lack of interest in the subject matter (Mäkinen, Olkinuora, \& Lonka, 2004) or questioning one's career choice (Hirsto, 2012).

In addition, Self-regulated learning (SRL; e.g., Boekaerts \& Cascallar, 2006; Pintrich, 2000; Vermunt, 1998; Wolters, Pintrich, \& Karabenick, 2005) is a key feature of what it means for students to be engaged in academic contexts (Wolters \& Taylor, 2012). Self-regulated students have more positive and fewer negative emotional experiences within academic settings (Linnenbrink \& Pintrich, 2000; Pekrun, Goetz, Titz, \& Perry, 2002; Schutz \& Davis, 2000), and are considered to be actively engaged in their own learning (Wolters, 2003; Zimmerman, 2002). But being self-regulated does not necessarily mean that the student has interest in the content. Students who have little interest can also effectively self-regulate (Sansone \& Thoman, 2005).

Finally, according to studies on work-related engagement (e.g., Schaufeli, Bakker, \& Salanova, 2006), study engagement describes the subject's psychological engagement in greater detail, emphasizing the affective component of engagement (Upadyaya \& Salmela-Aro, 2013). Within this framework, study engagement is typically described as a positive, fulfilling, study-related state of mind characterized by energy, dedication, and absorption (Salmela-Aro \& Upadyaya, 2012; Schaufeli et al., 2002). Rather than a momentary and specific state, such as flow (Csikszentmihalyi, 1990), the engagement described above refers to a more persistent and pervasive affective state (Schaufeli et al., 2002) that is positively related to academic performance (Salanova, Schaufeli, Martínez, \& Bresó, 2010; Salmela-Aro \& Upadyaya, 2012; Schaufeli et al., 2002; Tuominen-Soini \& Salmela-Aro, 2014).

\subsection{Problems in studying that predispose one to disengagement}

Disengagement is often defined as student burnout in terms of cynicism, inadequacy as a student and experiences of exhaustion (Salmela-Aro et al., 2009; Salmela-Aro \& Näätänen, 2005; Schaufeli et 
al., 2002). Of these, study-related exhaustion can be defined as feelings of strain, particularly chronic fatigue, resulting from taxing study (Schaufeli et al., 2002). In general, high exhaustion during studies is related to lower academic performance (Richardson et al., 2012; Stewart, Lam, Betson, Wong, \& Wong, 1999). When compared to older students, freshmen have been found to experience greater stress due to numerous changes, conflicts, and frustrations (M isra et al., 2000). Experiencing such a stress during the first academic year was a substantial barrier to obtaining a degree two years later (Vaez \& Laflamme, 2003).

A reasonable amount of stress, however, may be a sign of study commitment (Kember \& Leung, 2006) and exhaustion can be also experienced by engaged students (Daniels et al., 2008; Ketonen \& Lonka, 2013; Lonka \& Ketonen, 2012; Salmela-Aro, M oeller, Schneider, Spicer, \& Lavonen, 2016; Tuominen-Soini \& Salmela-Aro, 2014). Exhaustion may not be as strongly negatively related to study engagement as cynicism or sense of inadequacy as a student (Salmela-Aro et al., 2009; Tuominen-Soini \& Salmela-Aro, 2014). Thus, exhaustion may be an indicator of current study stress even in the right program, whereas finding little personal meaning in studies could be a sign of deeper, more enduring problems hindering academic engagement. When prolonged, however, exhaustion may start to affect one's well-being (M isra et al., 2000), predicting postgraduate exhaustion as well (Dahlin, Fjell, \& Runeson, 2010).

\subsubsection{Lack of personal meaning and cynicism in studying}

Experienced personal meaning may keep students motivated and committed despite challenges. Some students may be deeply interested in reflecting on the subject matter, whereas others may be more interested in directly applicable knowledge and their future profession (Lonka et al., 2008). Such practically oriented students have been found in all disciplines (Lonka \& Lindblom-Ylänne, 1996; M äkinen et al., 2004; Vermunt, 1996). Students may also select their majors merely because they find the subject matter interesting. Such study-oriented students refer to their enjoyment of studying and the desire to reflect on the subject (Byrne \& Flood, 2005). Both professionally and study-oriented students have been found to succeed better than those students who are still 
clarifying the personal meaning of their studying (Mäkinen et al., 2004).

Students who are certain about their career choice tend to be more successful in coping with the various educational demands of higher education (Germeijs \& Verschueren, 2007), whereas students uncertain or undecided about their career choice exhibit both lower academic performance and lower persistence rates (Leppel, 2001), and are less committed to studying (Germeijs \& Verschueren, 2007). However, some of the short-term negative consequences of early career indecision may ultimately lead to long-term positive consequences, particularly if better person-occupation fit is achieved as a result of extended search behavior (Betz \& Voyten, 1997; Lent, Brown, \& Hackett, 2000).

Both certainty of one's career choice and finding the subject matter meaningful are important dimensions of successful studying, but are not necessarily in harmony with each other. If students, even when committed to a career, find their majors to be meaningless, they may change majors or even drop out (Leppel, 2001). Lack of interest can be defined as deriving no personal meaning from studies due to finding the content unmotivating and it may lead to lower achievement and even drop out (Mäkinen et al., 2004). Undergraduate students' interest in their subject has been found to clearly decrease during the first year of studies (van der Veen, de Jong, van Leeuwen, $\&$ Korteweg, 2005).

\subsubsection{Lack of self-regulatory skills and feelings of inadequacy}

Even highly selected and well-motivated freshmen may face problems in self-regulation (Donche et al., 2010; Donche \& van Petegem, 2009; Nieminen et al., 2004). If the self-regulatory skills and demands of the learning environment are not balanced it may lead to friction between the student and the environment, which may be either constructive or destructive (Vermunt, 1996; Vermunt \& Verloop, 1999). The academic environment can challenge students with problems in self-regulation to develop their study practices and thus generate constructive friction (Lindblom-Ylänne \& Lonka, 2000). On the other hand, destructive friction may occur if the students' regulatory skills are good but the environment is heavily regulated by the teacher or if the academic environment does not 
provide enough external scaffolding and the student lacks the regulatory skills needed (Vermunt \& Verloop, 1999).

Constant destructive friction and problems in self-regulation may lead to feelings of inadequacy and greater exhaustion (Heikkilä et al., 2011; Lonka et al., 2008). Students with insufficient self-regulatory skills also have lower study success (Heikkilä et al., 2011; 2012; Heikkilä \& Lonka, 2006; Lonka \& Lindblom-Ylänne, 1996). However, students may learn to regulate over time (Donche et al., 2010; Donche \& van Petegem, 2009; Nieminen et al., 2004; Severiens, Ten Dam, \& Wolters, 2001; Vermetten et al., 1999; Vermunt \& M innaert, 2003), or when enough scaffolding is provided (Nicol \& Macfarlane-Dick, 2006; Zimmerman, 2002).

\subsection{The present study}

We suggest that during the first years of university studies the most relevant aspects of academic engagement are personal meaning in studying, self-regulated learning, and experiences of study engagement. Uncertainty of career choice, lack of meaning, problems in self-regulation, and exhaustion may instead hinder studying and lead to disengagement. In the present study we combined these theoretical perspectives to determine why some students perform better than others. The main objective was to form the academic engagement and disengagement profiles. Following a person-oriented approach (see Bergman \& M agnusson, 1997), we classified into homogenous groups the students with similar profiles of study engagement, study-related exhaustion, lack of interest in content, lack of self-regulation, and uncertainty of career choice. Second, by investigating whether the profiles differed in terms of academic achievement, we were able to examine the simultaneous effects of these dimensions on academic performance. The specific research questions were as follows:

(1) What kinds of academic engagement and disengagement profiles can be identified among undergraduate university students? 
We anticipated to found at least two subgroups: engaged and dysfunctional/disengaged students (Heikkilä et al., 2012; Ketonen \& Lonka 2013; Salmela-Aro et al., 2016; Tuominen-Soini \& SalmelaAro, 2014), but possibly also students being cynical or lacking interest in their studies (M äkinen et al., 2004; Tuominen-Soini \& Salmela-Aro, 2014).

(2) How do students with different academic engagement and disengagement profiles differ in terms of academic achievement (i.e., study credits and grades) during the same academic year and one year later?

It was assumed that engaged students would be more academically successful than their disengaged peers (Salanova et al., 2010; Salmela-Aro \& Upadyaya, 2012; Schaufeli et al., 2002; Tuominen-Soini \& Salmela-Aro, 2014). We further expected lower achievement to be more typical of students expressing uncertainty about their career choice or reporting lack of interest in content (M äkinen et al., 2004). Finally, achievement differences were anticipated to exist even after two years of studying (M äkinen et al., 2004).

\section{Method}

\subsection{Context of the study}

To be accepted into university in Finland, applicants must usually have a good diploma from high school and pass demanding subject-specific entrance examinations. Students choose their field of study before enrolling and are fairly confident about their disciplinary choices (Vuorinen \& Valkonen, 2005). The normative time for a combined Bachelor's and M aster's degree (300 ECTS credits) is five years, but the median duration is six (Universities, 2005). Since 2005, study time has been limited and the accumulation of credits monitored. Each student should earn at least 55 ECTS credits per academic year, and funding is partly allocated to universities on the basis of this. Finnish universities have no tuition fees for regular degree students. Students are also eligible for government-financed study grants. 


\subsection{Participants}

The participants consisted of 668 first- and second-year Finnish university students from four faculties from the University of Helsinki: law $(n=163)$, theology $(n=118)$, science $(n=117)$, and teacher education ${ }^{1}(n=199)$; and electrical engineering students $(n=71)$ from Aalto University. The participants were attending an introductory course in their faculty (and thus expected to be at the beginning of their studies). Their ages ranged from 18 to $58(M=24.2, S D=7.0) ; 425$ were female and 241 male. The overall response rate was $71.5 \%$, calculated on the basis of the number of students ( $n=934$ ) who completed the introductory courses in question.

\subsection{Measures}

\subsubsection{Study engagement}

Study engagement was assessed by an abbreviated student version of the short Utrecht Work Engagement Scale originally developed by Schaufeli et al. (UWES-9, 2006; Salmela-Aro \& Upadyaya, 2012). The scale consists of nine items related to studying in higher education measuring energy (e.g., "When I study, I feel I'm bursting with energy"), dedication (e.g., "I'm enthusiastic about my studies"), and absorption (e.g., "Time flies when I'm studying"). All items were rated on a Likert scale ranging from 1 (totally disagree) to 6 (totally agree). A composite scale was calculated from all nine items to indicate the overall level of study engagement. The Cronbach's alpha reliability was 0.90 .

\subsubsection{Problems in studying: exhaustion, lack of interest, and lack of self-regulation}

To measure problems in studying, we used scales that were previously found to be very diagnostic in predicting study disengagement and delays in the Nordic countries, especially in medicine (Lonka et al., 2008). Experienced exhaustion, lack of interest (i.e., lack of meaning), and lack of self-regulatory skills were explored using items from the M ED NORD questionnaire (Lonka et al., 2008), a collection of abbreviated versions of the original scales.

\footnotetext{
${ }^{1}$ Unlike many other countries, all primary school teachers in Finland are expected to have an M A degree in educational science or educational psychology.
} 
Study-related exhaustion (e.g., "I feel I'm working too hard on my studies") was measured with four items ( $\alpha=0.81$ ) taken from occupational health research and modified to fit the higher education context (M aslach \& Jackson, 1981). Experienced lack of interest, actually referring to studies having little meaning for students (e.g., "I can hardly find any meaning in the studies") was assessed with two items ( $\alpha=0.75$ ), originally from the Inventory of General Study Orientations (IGSO, M äkinen et al., 2004). Three items ( $\alpha=0.71$ ) concerning lack of self-regulation (e.g., "It is difficult for me to judge whether I know the study material well enough") were adopted originally from the Inventory of Learning Styles (ILS, Vermunt, 1998). Likert scales ranging from 1 (totally disagree) to 5 (totally agree) were used to rate each item.

\subsubsection{Uncertainty of career choice}

The questionnaire included three items $(\alpha=0.90)$ related to uncertainty of career choice, a recently found problem that is potentially harmful (e.g., "Another career choice might be more satisfying and closer to my goals"; Hirsto, 2012). A Likert scale ranging from 1 (totally disagree) to 5 (totally agree) was used to rate each item.

\subsubsection{Academic achievement}

Academic achievement data were retrieved from the universities' records. Academic achievement was operationalized as the accumulation of credits (ECTS) and as the mean of all grades (GPA) received by participants during the academic year when the questionnaire data were gathered (current performance), and the following academic year (students'second or third academic year). The academic grades range from one to five, with one indicating an adequate grade and five indicating excellent performance. Altogether 565 participants (84.6\%) gave their student number along with permission to merge the register data with the questionnaire data. Achievement statistics from the universities' archives were found for 548 participants (82.0\%) concerning current performance and for 514 (76.9\%) concerning the second year. 


\subsection{Procedure}

The self-report questionnaire data were collected from October through December, 2012, mid-way through the academic year. The data collection took place during mass introductory courses for freshmen. The questionnaire was either e-mailed to students through the courses' mailing lists or students completed a paper version during a lecture. The purpose of the study was explained to the participants and it was emphasized that participation was voluntary. All participants signed an informed consent form including consent to use and merge register data with the questionnaire data.

\subsection{Data analyses}

\subsubsection{Missing value analysis}

In the initial data screening the distributions and ranges were examined, and a M issing Value Analysis (M VA) was carried out. Because the missing values in the data ( $n=55,0.39 \%$ of all values) were missing completely at random (Little's M CAR test: Chi-Square $=213.94, D F=241, p=0.895$ ), we used the Full Information Maximum Likelihood (FIM L) method in the later analyses. The missing value per each item was five $(0.7 \%)$ or less.

\subsubsection{Latent profile analysis}

Students with similar patterns were identified through Latent Profile Analysis (LPA; see Pastor, Barron, Miller, \& Davis, 2007; Vermunt \& Magidson, 2002). LPA provides fit indices that enable comparison between different models and decision making regarding the number of underlying classes. Bayesian Information Criterion (BIC and adjusted BIC), and a Vuong-Lo-M endell-Rubin and Lo-M endell-Rubin adjusted likelihood ratio test (VLM R and LM R) were used as the statistical criteria for choosing the best-fitting model. The LPA model with the smallest information criteria values is considered to be the model of choice, and a $p$ value less than 0.05 for VLM R and LM R indicates that the model with one less class should be rejected in favor of the estimated model (Lo, Mendell, \& Rubin, 2001). The classification quality (i.e., entropy value) and the reasonableness of the latent 
classes in relation to theory and previous research were also considered to be criteria for choosing the best-fitting model. LPAs were conducted using the composite scores of the scales. In the models, all scales were allowed to correlate within the latent groups. Further, variances and covariances were assumed to be equal across classes.

After having established the student profiles, each participant was accorded a class based on the posterior probabilities of the LPA. We then conducted one-way ANOVAs and pairwise comparisons with the profile as an independent factor. First, the comparisons were conducted on the grouping variables to further investigate the differences between the profiles and the single variables' discriminating effects and second, on the achievement variables to examine group differences in performance. LPA was implemented using an M plus statistical package (Version 5.2; Muthén \& Muthén, 1998-2009) and MVA, ANOVAs and pairwise comparisons using IBM SPSS Statistics 22.0.

\section{Results}

\subsection{Preliminary results}

Correlations, descriptive statistics, and internal consistencies (i.e., Cronbach's alphas) of the profiling variables are presented in Table 1, showing that all scales indicated good internal consistencies. Study engagement was negatively related with all problems in studying, most strongly with lack of interest. Further, all problems in studying - especially uncertainty of career choice and lack of interest; and exhaustion and lack of self-regulation - correlated with each other. 
Table 1

Correlations, descriptive statistics, and internal consistencies of the scales.

\begin{tabular}{|c|c|c|c|c|c|}
\hline & 1 & 2 & 3 & 4 & 5 \\
\hline \multicolumn{6}{|l|}{1 Study engagement } \\
\hline 2 Exhaustion & $-.287^{* *}$ & & & & \\
\hline 3 Lack of interest & $-.659^{* *}$ & $.368^{* *}$ & & & \\
\hline 4 Lack of self-regulation & $-.325^{* *}$ & $.542^{* *}$ & $.374^{* *}$ & & \\
\hline 5 Uncertainty of career choice & $-.404^{* *}$ & $.222^{* *}$ & $.526^{* *}$ & $.218^{* *}$ & \\
\hline M & 4.09 & 2.52 & 2.00 & 2.75 & 2.15 \\
\hline SD & 0.77 & 0.90 & 0.92 & 0.92 & 1.10 \\
\hline Cronbach's alpha & 0.90 & 0.81 & 0.75 & 0.71 & 0.90 \\
\hline
\end{tabular}

\subsection{Academic engagement and disengagement profiles}

The first goal of the study was to examine the participants' academic engagement and disengagement profiles. The results from the series of LPAs (see Table 2) showed that BIC decreased when additional latent classes were added, up to the four-class solution, and also the VLMR and LM R tests provided clear support for the four-class solution. In addition, the average individual posterior probabilities for being assigned to a specific latent class were $0.97,0.89,0.91$, and 0.88 , respectively, indicating that the four-class model provided a clear distinction between latent groups. Furthermore, the reasonableness of the solutions in relation to theory and previous research were also considered to be criteria for choosing the four-class model. The four groups were labelled, according to the score mean profiles, as (1) engaged, (2) disengaged, (3) undecided, and (4) alienated (see Figure 1). 
Table 2

Information criteria values for different class solutions in LPAS.

\begin{tabular}{lllllll}
\hline N of classes & BIC & Adjusted BIC & PVLMR & PLMR & Entropy & Group sizes \\
\hline 1 & 8038.932 & 7975.431 & - & - & - & 668 \\
2 & 7898.161 & 7815.609 & 0.0000 & 0.0000 & 0.87 & 149,519 \\
3 & 7869.892 & 7768.290 & 0.2754 & 0.2831 & 0.86 & $49,152,467$ \\
4 & 7772.545 & 7651.892 & 0.0011 & 0.0013 & 0.89 & $59,95,52,462$ \\
5 & 7781.540 & 7641.838 & 0.2320 & 0.2382 & 0.90 & $60,9,459,51,89$ \\
6 & 7796.103 & 7637.349 & 0.4731 & 0.4815 & 0.89 & $9,449,58,72,54,26$ \\
\hline
\end{tabular}

Note. BIC =Bayesian Information Criterion; Adjusted BIC = adjusted Bayesian Information Criterion; PvLm =Vuong-LoMendell-Rubin likelihood ratio test; $P_{L M R}=$ Lo-Mendell-Rubin adjusted likelihood ratio test.

Engaged students ( $N=462,69 \%$ ) represented a typical, well-functioning student in the sample. In addition to having the highest certainty of career choice, they showed the highest study engagement and no problems in studying. Disengaged students $(\mathrm{N}=95,14 \%)$ showed the opposite: in addition to reporting high lack of interest and uncertainty about their career choice, they showed no study engagement, and instead, exhaustion and lack of self-regulation. Undecided students ( $N=59,9 \%)$ were as uncertain about their career choice as disengaged students, but were still found to have the second-highest study engagement and as little lack of interest, exhaustion and lack of self-regulation as engaged students. Finally, alienated students $(\mathrm{N}=52,8 \%)$ showed at the same time quite low uncertainty of career choice and high lack of interest. They also showed as little study engagement and as much exhaustion and lack of self-regulation as their disengaged peers. 


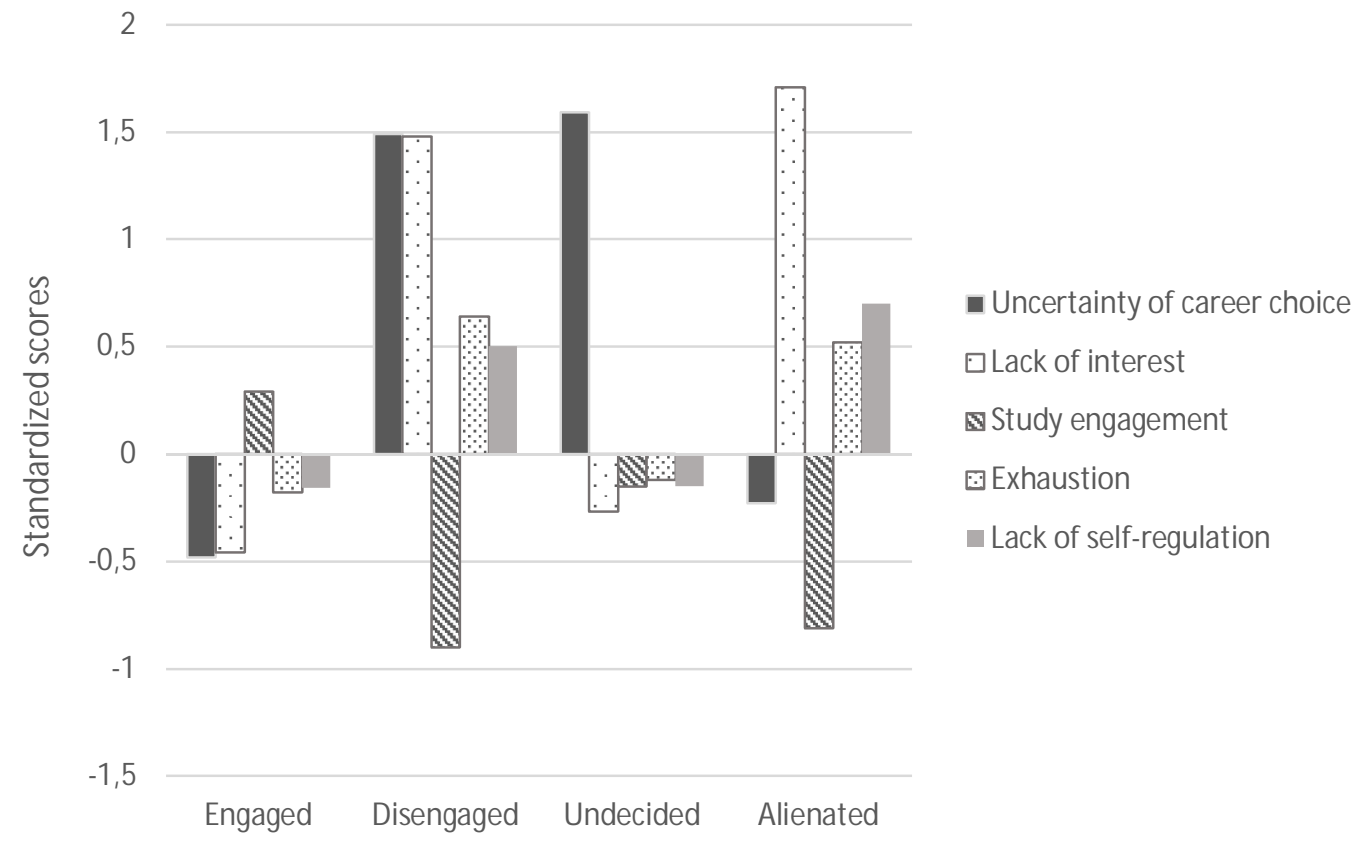

Figure 1. Students' academic engagement and disengagement profiles: standardized mean scores as a function of group membership.

Table 3 shows that uncertainty of career choice and lack of interest were the most discriminating variables between profiles with highest effect sizes. As Figure 1 illustrates, disengaged and undecided students expressed the highest uncertainty about their career choice, while alienated and in particular engaged students expressed high certainty. However, while engaged students were the most likely to experience their studies as meaningful (i.e., reporting the least lack of interest), alienated students reported the highest lack of interest. High lack of interest was also reported by disengaged students, while undecided students still found the content of their studies meaningful. Concerning the three remaining variables - study engagement, exhaustion and lack of selfregulation - the differences between these profiling variables were not particularly decisive, although statistically significant pairwise differences were found. 
Table 3

M ean differences in grouping variables between academic engagement and disengagement profiles

\begin{tabular}{|c|c|c|c|c|c|c|c|c|c|c|c|}
\hline \multirow[t]{2}{*}{ Variable } & \multicolumn{2}{|c|}{$\begin{array}{l}\text { Engaged } \\
N=462\end{array}$} & \multicolumn{2}{|c|}{$\begin{array}{l}\text { Disengaged } \\
N=95\end{array}$} & \multicolumn{2}{|c|}{$\begin{array}{l}\text { Undecided } \\
N=59\end{array}$} & \multicolumn{5}{|c|}{$\begin{array}{l}\text { Alienated } \\
\mathrm{N}=52\end{array}$} \\
\hline & M & SD & M & SD & $\mathrm{M}$ & SD & M & SD & $F(3,664)$ & $\mathrm{p}$ & $\eta^{2}$ \\
\hline Uncertainty of career choice & 1.62 & .58 & $3.79_{a}$ & .65 & $3.90_{a}$ & .61 & 1.89 & .62 & 527.25 & $<001$ & .71 \\
\hline Lack of interest & $1.55_{a}$ & .50 & $3.34 b$ & .55 & $1.73_{a}$ & .50 & $3.56_{b}$ & .56 & 500.96 & $<001$ & .69 \\
\hline Study engagement & 4.32 & .64 & $3.40_{b}$ & .71 & 3.98 & .77 & $3.47 \mathrm{~b}$ & .79 & 65.32 & $<001$ & .23 \\
\hline Exhaustion ${ }^{1}$ & $2.37 \mathrm{a}$ & .83 & $3.10_{b}$ & .91 & $2.42_{a}$ & .77 & $3.00_{b}$ & 1.05 & 25.17 & $<001$ & .10 \\
\hline Lack of self-regulation & $2.60 a$ & .88 & $3.21_{b}$ & .92 & $2.62 a$ & .78 & $3.40_{b}$ & .87 & 22.97 & $<001$ & .09 \\
\hline
\end{tabular}

Note. M eans within a row sharing the same subscripts are not significantly different at the $p<0.05$ level. Due to the unequal variances, a Games-Howell correction instead of Bonferroni was applied to the variables with 1.

\subsection{Differences between profiles in academic achievement}

Table 4 shows that regarding current performance, engaged students succeeded the best and disengaged and undecided students the worst in terms of both GPA and ECTS credits. Only the engaged students achieved the goal of 55 credits. After another academic year, the pattern had changed slightly. Still, the engaged students were the only group managing to reach 55 credits per year. However, a statistically significant difference was found only between the engaged and disengaged students after two years of studying. Further, differences between profiles in terms of GPA were no longer found.

Table 4

M ean differences in academic achievement between profiles

\begin{tabular}{|c|c|c|c|c|c|c|c|c|c|c|c|}
\hline \multirow[t]{2}{*}{ Variable } & \multicolumn{2}{|c|}{ Engaged } & \multicolumn{2}{|c|}{ Disengaged } & \multicolumn{2}{|c|}{ Undecided } & \multicolumn{5}{|c|}{ Alienated } \\
\hline & $M$ & SD & $M$ & SD & $M$ & SD & $M$ & SD & $\mathrm{F}$ & $p$ & $\eta^{2}$ \\
\hline GPA 1 1st year & $3.60_{a}$ & .74 & $3.10_{b}$ & .79 & $2.98 b$ & .87 & $3.36_{a b}$ & .77 & $F(3,540)=15.98$ & $<001$ & .08 \\
\hline GPA $2^{\text {nd }}$ year & $3.54 a$ & .71 & $3.35 a$ & .66 & $3.32 a$ & .52 & $3.41_{a}$ & .59 & $F(3,459)=2.16$ & .092 & .01 \\
\hline ECTS $1^{\text {st }}$ year $^{1}$ & $58.4 a$ & 18.8 & $43.4 b$ & 18.3 & $43.9_{b}$ & 22.7 & $54.6 a$ & 15.6 & $F(3,544)=19.40$ & $<001$ & .10 \\
\hline ECTS $2^{\text {nd }}$ year & $114.6_{a}$ & 35.2 & $99.9 \mathrm{~b}$ & 36.4 & $108.5_{a b}$ & 45.0 & $104.9_{a b}$ & 36.9 & $F(3,473)=3.18$ & .024 & .02 \\
\hline
\end{tabular}

Note. M eans within a row sharing the same subscripts are not significantly different at the $p<0.05$ level. Due to the unequal variances, a Games-Howell correction instead of Bonferroni was applied to the variables with 1. $1^{\text {st }}$ year refers to the year the questionnaire data were gathered (i.e., current performance), and $2^{\text {nd }}$ year to the following academic year (students' second or third academic year). 


\section{Discussion}

The academic engagement profiles of our participants varied considerably and were associated with academic achievement, even after two years of studying. In line with previous studies (Heikkilä et al., 2012; Ketonen \& Lonka 2013; Mäkinen et al., 2004; Salmela-Aro et al., 2016; Tuominen-Soini \& Salmela-Aro, 2014), we found the subgroups engaged and motivated students, students expressing disengagement and various problems in studying, and students lacking interest in their studies; but additionally, the group of undecided students. M ost undergraduate students were engaged, which is only natural since the participants were highly selected and studying on the basis of their own choice.

The engaged students were certain of their career choice, interested in their domain, and reported good self-regulatory skills, thus exhibiting a more study-oriented profile than the other groups. The study program seemed to meet their expectations and regulatory skills well. The disengaged and alienated students were the most dysfunctional. The disengaged students neither felt certain about their career choice nor saw the significance of their studies subject-wise. For the alienated students, inconsistency was found between high certainty of career choice and not finding the content interesting. In addition, both these groups reported problems in regulating their learning. These two groups also reported low study engagement and high exhaustion. Similar dysfunctional orientation was identified by Lonka et al. (2008) using a variable-centered approach, and Heikkilä et al. (2012) using a person-oriented approach. However, it is quite typical for exhaustion, increased workload, and lack of self-regulation to be experienced among freshmen (Lindblom-Ylänne \& Lonka, 2000; Litmanen, et al., 2014). Many of these students are coming directly from high school and still 'learning how to learn' in the academic community. In addition, they might already be exhausted due to demanding exams right before entering university. ${ }^{2}$

\footnotetext{
${ }^{2}$ For more about the Finnish higher education system, see Finnish national board of education (2016) Education system. Retrieved from http://www.oph.fi/english/education_system.
} 
The group of undecided students was interesting. Regardless of being the most uncertain about their career choice, these students still appeared quite functional: they reported relatively high study engagement and interest and as little exhaustion and lack of regulation as the engaged group. Particularly the experience of not being in the right place could explain why undecided students did not become exhausted, since commitment is often related to stress (Kember $\&$ Leung, 2006). The lower first-year achievement by undecided students was also likely due to a lack of commitment rather than other problems.

The disengaged and undecided students received the lowest grades and least credits after the first academic year, while engaged students had the most positive educational outcomes. Interestingly, despite the low study engagement and the least interest, the alienated students were still performing relatively well. This may be related to a practical orientation (e.g., Vermunt, 1996): even if alienated students were quite sure that they wanted to become lawyers, teachers, scientists, priests, or engineers, the study program somehow alienated them. Maybe they found the content of the courses or the manner in which they were taught either boring, irrelevant or too theoretical. Problems in self-regulation may also result from such mismatch. However, it may be precisely their high certainty of career choice that kept them going regardless of their low interest and insufficient self-regulatory skills. To sum, it appears that the general meaning of studying, either professional or content based, was related to success.

After another academic year, the engaged students were still receiving the most credits. At this point, however, the difference was found only between the engaged and disengaged students, and differences in GPA were no longer found. In the long run, only the group of disengaged students were left behind, while the undecided students in particular improved their performance. Their earlier career ambivalence had only short-term negative consequences on academic achievement. In addition, the most uncertain students had probably changed their discipline. 
In sum, the present study indicates that even highly selective admission to university does not automatically mean high engagement and success. Some students are engaged and do well, some are disengaged but still get along satisfactorily, some display both problems in studying and low motivation, and a small minority seem simply to be in the wrong place. These dispositions were related to the behavioral indicators of engagement (i.e., ECTS credits) even after two years of studying.

\subsection{Methodological reflections and future research}

Some limitations and suggestions for future research should be mentioned. First, the study was carried out in Finland and only included students from two universities. Several features of Finnish universities, such as the difficulty to enter them and lack of tuition fees, may mean that some of the findings could be different in other countries or higher education contexts. Second, the response rate is always a problem with student surveys (Porter \& Whitcomb, 2005). Based on our previous experience, gathering data from introductory course lectures provides the most comprehensive sample. We are aware, however, that perhaps only the more active students were reached via the lectures. Third, we used self-report measurements, which could have caused the results to be partly contaminated by common method variance. Nevertheless, the aim was to particularly investigate students' own experiences of their engagement. Furthermore, we also used objective measures of behavioral indicators of engagement (i.e., academic achievement variables), meaning that the common method variance problem is less serious for these key outcome variables.

The measures used in the present study concerned studying in general. Although it is interesting to examine students' overall engagement, it is nevertheless reasonable to assume that these motivational dispositions may differ not only between disciplines, but also between courses with different contents, physical environments, and pedagogical methods. Using alternative methods, such as an experience sampling approach (Hektner, Schmidt, \& Csikszentmihalyi, 2007; see also Inkinen et al., 2014; Litmanen, Lonka, Inkinen, Lipponen, \& Hakkarainen, 2012), we shall better understand not only the general and contextual nature of academic engagement, but also the 
potential fluctuations in momentary engagement. Finally, our future study will reveal how the students' academic engagement profiles develop during studies and how they predict later engagement and educational outcomes. Is the high engagement in the beginning of university studies due to a "honeymoon effect" rather than a stable disposition? We hypothesize that the profiles begin to form when first contact with the academic environment is established, but are dynamic in nature.

\subsection{Implication for education}

Despite its limitations, the present study has several strengths. The study contributes to the growing research field of academic engagement (e.g., Fredricks et al., 2004). It is alarming that even after two academic years only the group of engaged students achieved the goal of 55 ECTS credits per year. Failing to address this government goal has significant economic consequences for the institutions and indirectly for students as well. Since almost a third of the participants were uncertain about their career choices, the focus should be on student selection to find the most devoted applicants. In addition, sufficient career counselling already in secondary school would help guide students to begin their studies in an optimal discipline.

As well as lacking personal meaning in studying, students may have low engagement because of self-regulation problems. With adequate instructional scaffolding, this friction can be made more constructive (Vermunt \& Verloop, 1999). However, the problem may not always be a lack of commitment or self-regulatory skills. Discrepancies between students' expectations and the practices of the study program may also result in a loss of interest. Further, we can ask whether or not we want to select only the students who are already well-motivated, and whether or not interest can be triggered and fostered during the first years of study. We believe that interest is not a fixed state, but rather a varying and developing experience that one can affect by instructional arrangements (Hidi \& Renninger, 2006). 
To conclude, recognizing the different student profiles can make it easier to provide students with tailored support. It is important not to blame only the individual or the environment, but to take both into account as well as the balance between them. Accordingly, both universities and students themselves can affect the quality of this fit. The opportunity to engage students may lie in the ability to shape and influence the whole learning environment: how to design more engaging learning environments for universities, as well as introduce increasingly engaging pedagogical practices (see Lonka \& Ketonen, 2012). The already engaged should not be forgotten either: How can we deepen their interest and maintain their level of engagement?

\subsection{Conclusions}

The theoretical bases of student engagement, self-regulated learning, and the emotional experiences that are included were used in the present study to help understand why some students are successful and others are not. The aim was to provide greater insight into the relations between these theoretical frameworks. An obvious conclusion therefore, is that the research on these dimensions of studying should be integrated to a greater extent in order to better understand and improve students' functioning within academic contexts. Further, by using a person-oriented approach, we were able to identify individual patterns among subgroups of students and the challenges they are facing during the first years at university.

In both the correlational and profile results, lack of interest was related to lower study engagement as well as higher exhaustion and lack of regulatory skills. While many studies have found lack of interest to be very decisive (e.g., M äkinen et al., 2004; Stubb, Pyhältö, \& Lonka, 2012), our study highlighted the significance of uncertainty of career choice. The uncertainty of career choice and lack of interest most clearly determined the student profiles in the present study. However, closer examination of these two variables showed that they behave in different ways: by simply looking at the correlational results, it seemed that the less uncertainty of career choice there was, the less lack of interest and more study engagement was reported. However, by using a personoriented approach we were able to reveal the more complex interplay between these variables. 
Unlike in the correlational results, a low uncertainty of career choice was related to both low (engaged students) and high lack of interest (alienated students) in the profiles. Further, a strong certainty of career choice did not necessarily mean high study engagement (alienated students), and without being completely sure about career choice, one could still experience meaning and engagement in the subject (undecided students). Without applying a person-oriented approach and profiling the students, we would not have detected these different patterns of the investigated dimensions, and which of the dimensions were the most critical.

It might be the case that study engagement, exhaustion, and regulatory skills are more closely related to everyday studying and the given academic environment, while the question of one's career choice and the meaningfulness of one's studies may be more stable dimensions, coloring these contextual experiences. To test these hypotheses, longitudinal data and modeling as well as the above-mentioned contextual measurements should be used in future research. It is evident, however, that individual differences in academic engagement already exist in the early stage of university studies.

\section{Acknowledgements}

This research was funded by The Finnish Funding Agency for Technology and Innovation (TEKES) project 'RYM Indoor Environment' (462054), and The Academy of Finland M ind Program project 'Mind the Gap' (265528). 


\section{References}

Allen, J., \& Robbins, S. B. (2008). Prediction of college major persistence based on vocational interests, academic preparation, and first-year academic performance. Research in Higher Education, 49(1), 62-79.

Appleton, J. J., Christenson, S. L., \& Furlong, M. J. (2008). Student engagement with school: Critical conceptual and methodological issues of the construct. Psychology in the Schools, 45(5), 369-386.

Appleton, J. J., Christenson, S. L., Kim, D., \& Reschly, A. L. (2006). Measuring cognitive and psychological engagement: Validation of the Student Engagement Instrument. Journal of School Psychology, 44(5), 427-445.

Astin, A. W. (1993). What matters in college? Four critical years revisited. San Francisco: Jossey-Bass.

Bergman, L. R., \& Andersson, H. (2010). The person and the variable in developmental psychology. Zeitschrift für Psychologie, 218, 155-165.

Bergman, L. R., \& M agnusson, D. (1997). A person-oriented approach in research on developmental psychopathology. Development and Psychopathology, 9(2), 291-319.

Betz, N. E., \& Voyten, K. K. (1997). Efficacy and outcome expectations influence career exploration and decidedness. The Career Development Quarterly, 46(2), 179-189.

Blythman, M ., \& Orr, S. (2003). A joined-up policy approach to student support. In M. Peelo, \& T. Wareham (Eds.), Failing students in higher education (pp. 45-55). Buckingham: Open University Press.

Boekaerts, M ., \& Cascallar, E. (2006). How far have we moved toward the integration of theory and practice in self-regulation? Educational Psychology Review, 18(3), 199-210.

Byrne, M., \& Flood, B. (2005). A study of accounting students' motives, expectations and preparedness for higher education. J ournal of Further and Higher Education, 29(2), 111-124.

Csikszentmihalyi, M. (1990). Flow. The psychology of optimal experience. New York: HarperPerennial.

Dahlin, M., Fjell, J., \& Runeson, B. (2010). Factors at medical school and work related to exhaustion among physicians in their first postgraduate year. Nordic Journal of Psychiatry, 64(6), 402-408.

Daniels, L. M., Haynes, T. L., Stupnisky, R. H., Perry, R. P., Newall, N. E., \& Pekrun, R. (2008). Individual differences in achievement goals: A longitudinal study of cognitive, emotional, and achievement outcomes. Contemporary Educational Psychology, 33(4), 584-608.

Donche, V., Coertjens, L., \& van Petegem, P. (2010). Learning pattern development throughout higher education: A longitudinal study. Learning and Individual Differences, 20(3), 256-259.

Donche, V., \& van Petegem, P. (2009). The development of learning patterns of student teachers: a cross-sectional and longitudinal study. Higher Education, 57(4), 463-475. 
Entwistle, N. J., \& Peterson, E. R. (2004). Conceptions of learning and knowledge in higher education: Relationships with study behaviour and influences of learning environments. International Journal of Educational Research, 41(6), 407-428.

Fredricks, J. A., Blumenfeld, P. C., \& Paris, A. H. (2004). School engagement: Potential of the concept, state of the evidence. Review of Educational Research, 74(1), 59-109.

Germeijs, V., \& Verschueren, K. (2007). High school students' career decision-making process: Consequences for choice implementation in higher education. Journal of Vocational Behavior, 70(2), 223-241.

Gilbreath, B., Kim, T.-Y., \& Nichols, B. (2011). Person-environment fit and its effects on university students: A response surface methodology study. Research in Higher Education, 52(1), 47-62.

González-Romá, V., Schaufeli, W. B., Bakker, A. B., \& Lloret, S. (2006). Burnout and work engagement: Independent factors or opposite poles? Journal of Vocational Behavior, 68(1), 165-174.

Hakanen, J. J., Bakker, A. B., \& Schaufeli, W. B. (2006). Burnout and work engagement among teachers. Journal of School Psychology, 43(6), 495-513.

Heikkilä, A., \& Lonka, K. (2006). Studying in higher education: students' approaches to learning, selfregulation, and cognitive strategies. Studies in Higher Education, 31(1), 99-117.

Heikkilä, A., Lonka, K., Nieminen, J., \& Niemivirta, M . (2012). Relations between teacher students' approaches to learning, cognitive and attributional strategies, well-being, and study success. Higher Education, 64(4), 455-471.

Heikkilä, A., Niemivirta, M., Nieminen, J., \& Lonka, K. (2011). Interrelations among university students' approaches to learning, regulation of learning, and cognitive and attributional strategies: a person oriented approach. Higher Education, 61(5), 513-529.

Hektner, J. M ., Schmidt, J. A., \& Csikszentmihalyi, M. (2007). Experience sampling method: M easuring the quality of everyday life. Thousand Oaks, CA: Sage.

Hidi, S., \& Renninger, K. A. (2006). The four-phase model of interest development. Educational Psychologist, 41(2), 111-127.

Hirsto, L. (2012). Certainty of career choice at the beginning of university studies-general strategies and attributions in achievement situations, and career motives. Studies for the Learning Society, 2(23), 35-45.

Inkinen, M., Lonka, K., Hakkarainen, K., Muukkonen, H., Litmanen, T., \& Salmela-Aro, K. (2014). The interface between core affects and the challenge-skill relationship. Journal of Happiness Studies, 15(4), 891-913.

Jimerson, S. R., Campos, E., \& Greif, J. L. (2003). Toward an understanding of definitions and measures of school engagement and related terms. The California School Psychologist, 8(1), 7-27. 
Johnson, G.M . (1994). Undergraduate student attrition: a comparison of the characteristics of students who withdraw and students who persist. Alberta Journal of Educational Research, 40(3), 337-353.

Kember, D., \& Leung, D. Y. (2006). Characterizing a teaching and learning environment conducive to making demands on students while not making their workload excessive. Studies in Higher Education, 31(2), 185-198.

Ketonen, E., \& Lonka, K. (2013). How are situational academic emotions related to teacher students' general learning profiles? In Tirri, K. \& Kuusisto, E. (Eds.), Interaction in educational domains (pp. 103-114). Rotterdam: Sense Publishers.

Lent, R. W., Brown, S. D., \& Hackett, G. (2000). Contextual supports and barriers to career choice: A social cognitive analysis. Journal of Counseling Psychology, 47(1), 36-49.

Leppel, K. (2001). The impact of major on college persistence among freshmen. Higher Education, 41(3), 327-342.

Lindblom-Ylänne, S., \& Lonka, K. (2000). Dissonant study orchestrations of high-achieving university students. European Journal of Psychology of Education, 15(1), 19-32.

Linnenbrink, E., \& Pintrich, P. (2000). Multiple pathways to learning and achievement: The role of goal orientation in fostering adaptive motivation, affect, and cognition. In C. Sansone, \& J. Harackiewicz (Eds.), Intrinsic and extrinsic motivation: The search for optimal motivation and performance (pp. 195-254). San Diego, CA: Academic.

Litmanen, T., Lonka, K., Inkinen, M., Lipponen, L., \& Hakkarainen, K. (2012). Capturing teacher students' emotional experiences in context: does inquiry-based learning make a difference? Instructional Science, 40(6), 1083-1101.

Litmanen, T., Loyens, S., Sjöblom, K., \& Lonka, K. (2014). M edical students' perceptions of their learning environment, well-being and academic self-concept. Creative Education, 5(21), 1856-1868.

Lo, Y., M endell, N. R., \& Rubin, D. B. (2001). Testing the number of components in a normal mixture. Biometrika, 88(3), 767-778.

Lonka, K., \& Ketonen, E. (2012). How to make a lecture course an engaging learning experience? Studies for the Learning Society, 2(2-3), 63-74.

Lonka, K., \& Lindblom-Ylänne, S. (1996). Epistemologies, conceptions of learning, and study practices in medicine and psychology. Higher Education, 31(1), 5-24.

Lonka, K., Sharafi, P., Karlgren, K., M asiello, I., Nieminen, J., Birgegård, G., \& Josephson, A. (2008). MED NORD - A tool for measuring medical students' well-being and study orientations. Medical Teacher, 30(1), 72-79.

Maslach, C., \& Jackson, S. E. (1981). The measurement of experienced burnout. Journal of Organizational Behavior, 2(2), 99-113. 
M clnnis, C., \& James, R., \& M cNaught, C. (1995). First year on campus: Diversity in the initial experiences of Australian Graduates. Committee for the Advancement of University Teaching. Canberra: AGPS.

M isra, R., M cKean, M., West, S., \& Russo, T. (2000). Academic stress of college students: Comparison of student and faculty perceptions. College Student Journal, 34(2), 236-245.

M uthén, L. K., \& M uthén, B. O. (1998-2009). M plus. Statistical analyses with latent variables. User's guide (5th ed.). Los Angeles, CA: Muthén $\&$ Muthén.

M äkinen, J., Olkinuora, E., \& Lonka, K. (2004). Students at risk: Students' general study orientations and abandoning/prolonging the course of studies. Higher Education, 48(2), 173-188.

Nicol, D. J., \& Macfarlane-Dick, D. (2006). Formative assessment and self-regulated learning: A model and seven principles of good feedback practice. Studies in Higher Education, 31(2), 199-218.

Nieminen, J., Lindblom-Ylänne, S., \& Lonka, K. (2004). The development of study orientations and study success in students of pharmacy. Instructional Science, 32(5), 387-417.

Pascarella, E. T., \& Terenzini, P. T. (1991). How college affects students: Findings and insights from twenty years of research. San Francisco: Jossey-Bass.

Pastor, D. A., Barron, K. E., Miller, B. J., and Davis, S. L., 2007. A latent profile analysis of college students' achievement goal orientation. Contemporary Educational Psychology, 32(1), 8-47.

Pekrun, R., Goetz, T., Titz, W., \& Perry, R. P. (2002). Academic emotions in students' self-regulated learning and achievement: A program of qualitative and quantitative research. Educational Psychologist, 37(2), 91-105.

Pekrun, R., \& Linnenbrink-Garcia, L. (2012). Academic emotions and student engagement. In S. L. Christenson, A. L. Reschly, \& C. Wylie (Eds.), The handbook of research on student engagement (pp. 259-282). New York: Springer.

Pintrich, P. (2000). The role of goal orientation in self-regulated learning. In M. Boekaerts, P. Pintrich, $\&$ M. Zeidner (Eds.), Handbook of self-regulation (pp. 451-502). San Diego, CA: Academic.

Porter, S. R., \& Umbach, P. D. (2006). College major choice: An analysis of person-environment fit. Research in Higher Education, 47(4), 429-449.

Porter, S. R., \& Whitcomb, M. E., 2005. Non-response in student surveys: The role of demographics, engagement and personality. Research in Higher Education, 46(2), 127-152.

Reizle, M. (2013). Introduction: Doubts and insights concerning variable- and person-oriented approaches to human development. European Journal of Developmental Psychology, 10(1), 1-8.

Richardson, M ., Abraham, C., \& Bond, R. (2012). Psychological correlates of university students' academic performance: a systematic review and meta-analysis. Psychological Bulletin, 138(2), 353387. 
Salanova, M ., Schaufeli, W., Martínez, I., \& Bresó, E. (2010). How obstacles and facilitators predict academic performance: The mediating role of study burnout and engagement. Anxiety, Stress $\&$ Coping, 23(1), 53-70.

Salmela-Aro, K., Kiuru, N., Leskinen, E., \& Nurmi, J. E. (2009). School Burnout Inventory (SBI): Reliability and validity. European Journal of Psychological Assessment, 25(1), 48-57.

Salmela-Aro, K., M oeller, J., Schneider, B., Spicer, J., \& Lavonen, J. (2016). Integrating the light and dark sides of student engagement using person-oriented and situation-specific approaches. Learning and Instruction, 43, 61-70.

Salmela-Aro, K., \& Näätänen, P. (2005). M ethod of assessing adolescents' school burnout. Helsinki, Finland: Edita.

Salmela-Aro, K., \& Upadyaya, K. (2012). The Schoolwork Engagement Inventory: Energy, dedication, and absorption (EDA). European Journal of Psychological Assessment, 28(1), 60-67.

Sansone, C., \& Thoman, D. B. (2005). Interest as the missing motivator in self-Regulation. European Psychologist, 10(3), 175-186.

Schaufeli, W. B., Bakker, A. B., \& Salanova, M . (2006). The measurement of work engagement with a short questionnaire a cross-national study. Educational and Psychological Measurement, 66(4), 701716.

Schaufeli, W. B., Martínez, I. M., Pinto, A. M., Salanova, M., \& Bakker, A. B. (2002). Burnout and engagement in university students a cross-national study. Journal of Cross-cultural Psychology, 33(5), 464-481.

Schmitt, N., Oswald, F. L., Friede, A., Imus, A., \& Merritt, S. (2008). Perceived fit with an academic environment: Attitudinal and behavioral outcomes. Journal of Vocational Behavior, 72(3), 317-335.

Schutz, P. A., \& Davis, H. A. (2000). Emotions and self-regulation during test taking. Educational Psychologist, 35(4), 243-256.

Severiens, S., Ten Dam, G., \& Wolters, B. V. H. (2001). Stability of processing and regulation strategies: Two longitudinal studies on student learning. Higher Education, 42(4), 437-453.

Stewart, S. M., Lam, T. H., Betson, C. L., Wong, C. M., \& Wong, A. M. P. (1999). A prospective analysis of stress and academic performance in the first two years of medical school. M edical EducationOxford, 33(4), 243-250.

Stubb, J., Pyhältö, K., \& Lonka, K. (2012). The experienced meaning of working with a PhD thesis. Scandinavian J ournal of Educational Research, 56(4), 439-456.

Tinto, V. (1996). Reconstructing the first year of college. Planning for Higher Education, 25(1), 1-6.

Tracey, T. J., \& Robbins, S. B. (2006). The interest-major congruence and college success relation: A longitudinal study. Journal of Vocational Behavior, 69(1), 64-89. 
Trigwell, K., \& Prosser, M . (1991). Improving the quality of student learning: the influence of learning context and student approaches to learning on learning outcomes. Higher Education, 22(3), 251-266.

Tuominen-Soini, H., \& Salmela-Aro, K. (2014). Schoolwork engagement and burnout among Finnish high school students and young adults: Profiles, progressions, and educational outcomes. Developmental Psychology, 50(3), 649.

Universities 2005. Annual report. Helsinki, Finland: M inistry of Education Publications, 2006.

Upadyaya, K., \& Salmela-Aro, K. (2013). Engagement with studies and work: trajectories from postcomprehensive school education to higher education and work. Emerging Adulthood, 1(4), 247-257.

Vaez, M., \& Laflamme, L. (2003). Health behaviors, self-rated health, and quality of life: a study among first-year Swedish university students. J ournal of American College Health, 51(4), 156-162.

Vanderstoep, S. W., Pintrich, P. R., \& Fagerlin, A. (1996). Disciplinary differences in self-regulated learning in college students. Contemporary Educational Psychology, 21(4), 345-362.

Van der Veen, I. V. D., de Jong, U. D., van Leeuwen, M. V., \& Korteweg, J. A. (2005). The development of higher education students' interest in their subject: The case of higher professional education in the Netherlands. Studies in Higher Education, 30(3), 275-289.

Vermetten, Y. J., Vermunt, J. D., \& Lodewijks, H. G. (1999). A longitudinal perspective on learning strategies in higher education-different view-points towards development. British Journal of Educational Psychology, 69(2), 221-242.

Vermunt, J. D. (1996). M etacognitive, cognitive and affective aspects of learning styles and strategies: A phenomenographic analysis. Higher Education, 31(1), 25-50.

Vermunt, J. D. (1998). The regulation of constructive learning processes. British Journal of Educational Psychology, 68(2), 149-171.

Vermunt, J. K., \& Magidson, J. (2002). Latent class cluster analysis. In J. A. Hagenaars \& A. L. M cCutcheon (Eds.), Applied latent class analysis (pp. 89-106). Cambridge, United Kingdom: Cambridge University Press.

Vermunt, J., \& Minnaert, A. (2003). Dissonance in student learning patterns: when to revise theory? Studies in Higher Education, 28(1), 49-61.

Vermunt, J. D., Richardson, J. T. E., Donche, V., \& Gijbels, D. (2013). Students' learning patterns in higher education: Dimensions, measurement and change. In D. Gijbels, V. Donche, J.T.E. Richardson, \& J.D. Vermunt (Eds.), Learning patterns in higher education: Dimensions and research perspectives. London: Routledge.

Vermunt, J. D., \& Verloop, N. (1999). Congruence and friction between learning and teaching. Learning and Instruction, 9(3), 257-280.

Vuorinen, P., \& Valkonen, S. (2005). Ammattikorkeakoulu ja yliopisto yksilöllisten koulutustoiveiden toteuttajana [Polytechnics and universities as a path to individual educational goals; in Finnish]. University of Jyväskylä Institute for Educational Research, Occasional papers 25. 
Wolters, C. A. (2003). Regulation of motivation: Evaluating an underemphasized aspect of selfregulated learning. Educational Psychologist, 38(4), 189-205.

Wolters, C., Pintrich, P., \& Karabenick, S. (2005). Assessing academic self-regulated learning. In K. Moore, \& L. Lippman (Eds.), What do children need to flourish? Conceptualizing and measuring indicators of positive development (pp. 251-270). New York: Springer.

Wolters, C. A., \& Taylor, D. J. (2012). A self-regulated learning perspective on student engagement. In S. L. Christenson, A. L. Reschly, \& C. Wylie (Eds.), Handbook of research on student engagement (pp. 635-652). New York, NY: Springer.

Zimmerman, B. J. (2002). Becoming a self-regulated learner: An overview. Theory into Practice, 41(2), 64-70. 